$$
\text { CONF- } 9011115--2
$$

UCRL-JC-103502

PREPRINT

\title{
COMPUTATIONAL AND EXPERIMENTAL PROGRESS ON LASER-ACTIVATED GAS AVALANCHE SWITCHES FOR BROADBAND, HIGH-POWER ELECTROMAGNETIC PULSE GENERATION
}

\author{
David J. Mayhall \\ Jick H. Yee \\ and \\ Francesco Villa
}

This paper was prepared for submittal to

the SPIE Intemational Symposium,

Applications in Optical Science and

Engineering, Laser Science and Optics

Applications, Optically Activaled Switching,

Boston, MA, 11/5-6/90

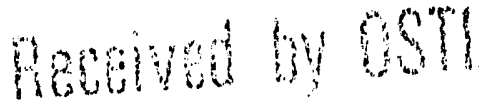

NOV 051990

September 1990
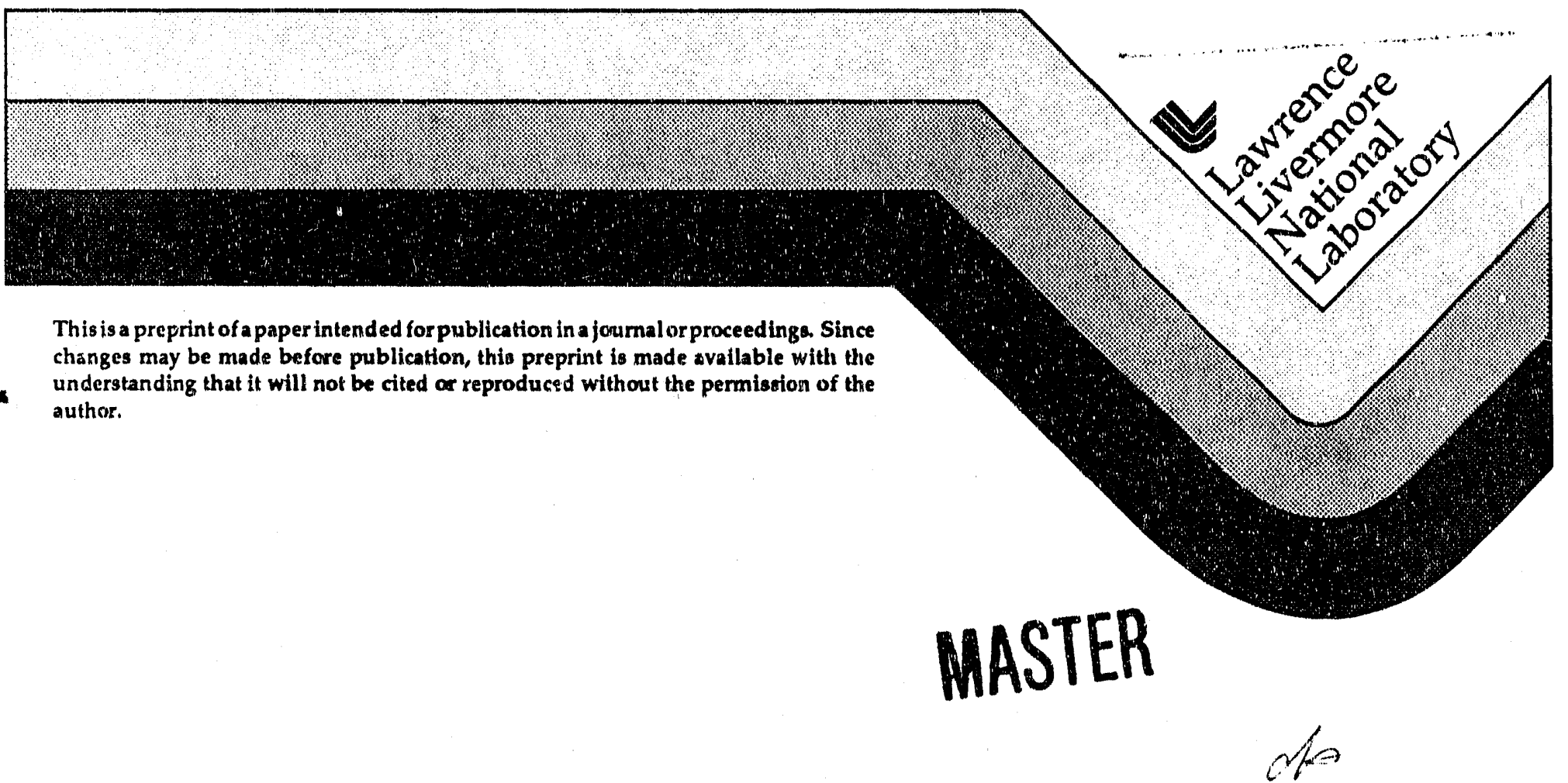
DISCLAIMER

This document was prepared as an account of work sponsored by an agency of the United States Government. Neither the United States Government nor the University of California nor any of their employees, makes any warranty, express or implied, or assumes any legal liability or responsibility for the accuracy, completeness, or usefulness of any information, apparatus, product, or process disclosed, or represents that its wse would not infringe privately ouned rights. Reference herein to any specific cummercial products. process, or service by trade name, trademark, manufacturer, or otherwise, does not necessarily constitute or imply its endorsement, recommendation, or favoring by the IInited States Gevernment or the University of California. The views and opinions of authors expressed herein do not necessariy itate or rellect those of the United States Government or the University of California, and shall not be used for advertising or product endorsement purposes. 
Computational and experimental progress on laser-activated gas avalanche switches for broadband, high-power electromagnetic pulse generation ${ }^{*}$

David J. Mayhall and Jick H. Yee

Lawrence Livermore National Laboratory, University of California

P.O. Box 808, L-156, Livermore, CA 94550

Francesco Villa

UCRL $-J C--103502$

Stenford Linear Accelerator Center

P.O. Box 4349, Mail Bin 65, Stanford, CA 94305

DE91 001763

\begin{abstract}
The gas avalanche switch, a high-voltage, picosecond-speed switch, has been proposed. The basic switch consists of pulse-charged electrodes, immersed in a high-pressure (7-800 atm) gas. An avalanche discharge is induced in the gas between the electrodes by ionization from a picosecond-scale laser pulse. The avalanching electrons move toward the anode, causing the applied voltage to collapse in picoseconds. This voltage collapse, if rapid enough, generates electromagnetic waves. A two-dimensional (2D), finite difference computer code solves Maxwell's equations for transverse magnetic modes for rectilinear electrodes between parallel plate conductors, along with electron conservation equations for continuity, momentum, and energy. Collision frequencies for ionization and momentum and energy transfer to neutral molecules are assumed to scale linearly with neutral pressure. Electrode charging and laser-driven electron deposition are assumed to be instantaneous.
\end{abstract}

Code calculations are done for a pulse generator geometry, consisting of an $0.7 \mathrm{~mm}$ wide by $0.8 \mathrm{~mm}$ high, beveled, rectangular center electrode betw zen grounded parallel plates at $2 \mathrm{~mm}$ spacing in air. In one operational mode, a uniform distribution of initial electrons is induced in the gap between the center electrode and the lower plate. With the center electrode at $227 \mathrm{kV}$ positive and $15 \mathrm{~atm}$ pressure, voltage pulses of $241 \mathrm{kV}, 2$ ps rise times, $8 \mathrm{ps}$ full widths at half maximum (FWHM), 30 ps durations, and $24 \mathrm{GHz} 3 \mathrm{~dB}$ bandwidths are induced at the ends of the plates by passing electromagnetic waves. Similar pulses occur at $292 \mathrm{kV}, 27 \mathrm{~atm}$ and $3.9 \mathrm{MV}, 700 \mathrm{~atm}$. Slower pulses are generated at $49 \mathrm{kV}$ and $8 \mathrm{~atm}$. In another operational mode, delayed laser pulses induce ionization in both the lower and the upper gas gaps. Voltage pulses of reduced FWHMs (1.1-1.8 ps) and amplitudes (7-51 kV) are then generated by interfering electromagnetic waves from the two gaps.

Preliminary voltage holdoff tests with an overvolted series stripline switch, having knife edge to slightly concave cylindrical electrodes and a $102 \mu \mathrm{m}$ gap, show holdoff times of $2-6 \mathrm{~ns}$. The excitation is an irregular ac charging pulse for conditions up to $56 \mathrm{kV}$ and $14 \mathrm{~atm}$ in nitrogen.

\title{
1. INTRODUCTION
}

Recently, a promising candidate for picosecond, high-voltage switching, the gas avalanche switch, was proposed. 1,2 The basic switch consists of a set of pulse-charged electrodes, immersed in a high-pressure (7-800 atm) gas. An avalanche discharge is induced in the gas between the electrodes by ionization from a picosecond-scale laser pulse. The laser-initiated electrons rapidly avalanche toward the anode in the applied electric field. This rapid avalanche, fueled by the large number of available electrons in the high-pressure gas, causes the applied voltage across the electrodes to collapse in picoseconds. This voltage collapse occurs long before the hot channel formation in a conventional spark gap.

\footnotetext{
* Work performed under the auspices of the U.S. Department of Energy by Lawrence Livermore National Laboratory under Contract W-7405-Eng-48.
} 
Several versions of the gas avalanche switch are possible. A simple parallel plate capacitor version consists of a highpressure gas confined between two parallel metal plates. An analysis of the voltage delay and collapse times for this switch has been done by Villa ${ }^{1}$ and Cassell and Villa. ${ }^{2}$ These researchers performed numerical time integration of a zero-

üimensional, electric circuit equation based on Kirchoff's laws. This current node equation included a resistively limited charge feed and a constant power supply voltage. This analysis predicted voltage collapse times of several picoseconds for nitrogen and air and $1 \mathrm{ps}$ or less for argon. These results were for a plate spacing or gap of $100 \mu \mathrm{m}$.

\section{A TWO-DIMENSIONAL, ELECTROMAGNETIC, ELECTRON FLUID CODE}

To confirm the encouraging predictions of the circuit analysis mentioned previously, we have developed a 2D computer code, GAS2D, which simultaneously and self-consistently solves Maxwell's equations for transverse magnetic field modes in a gas between two parallel perfect conductors and a set of electron fluid conservation equations. These conservation equations are for continuity, momentum, and energy. One or more rectilinear, perfectly conducting electrodes may be placed between the plates.

\subsection{Governing equations}

For: a free space dielectric between the plates, the relevant Maxwell's equations in the MKS system are

$$
\begin{aligned}
& \frac{\partial \mathrm{E}_{\mathrm{x}}}{\partial \mathrm{t}}=\frac{1}{\varepsilon_{\mathrm{o}}} \frac{\partial \mathrm{H}_{\mathrm{z}}}{\partial \mathrm{y}}-\frac{n e v_{\mathrm{x}}}{\varepsilon_{\mathrm{o}}}, \\
& \frac{\partial \mathrm{E}_{\mathrm{y}}}{\partial \mathrm{t}}=-\frac{1}{\varepsilon_{\mathrm{o}}} \frac{\partial \mathrm{H}_{\mathrm{z}}}{\partial \mathrm{x}}-\frac{\mathrm{nev}_{\mathrm{y}}}{\varepsilon_{\mathrm{o}}}, \\
& \frac{\partial \mathrm{H}_{\mathrm{z}}}{\partial \mathrm{t}}=\frac{1}{\mu_{\mathrm{o}}} \frac{\partial \mathrm{E}_{\mathrm{x}}}{\partial \mathrm{y}}-\frac{1}{\mu_{\mathrm{o}}} \frac{\partial \mathrm{E}_{\mathrm{y}}}{\partial \mathrm{x}},
\end{aligned}
$$

where $E_{x}$ is the electric field component in the $x$ direction, $E_{y}$ is the electric field component in the $y$ direction, $H_{z}$ is the magnetic field component in the $z$ direction, $\varepsilon_{0}$ is the free space permittivity, $n$ is the electron density, $e$ is the electron charge $\left(1.6 \times 10^{-19} \mathrm{C}\right), v_{x}$ is the electron velocity in the $x$ direction, $v_{y}$ is the electron velocity in the $y$ direction, and $\mu_{0}$ is the free space permeability.

The electron fluid equations are

$$
\begin{aligned}
& \frac{\partial n}{\partial t}=n v_{i}, \\
& \frac{\partial\left(n v_{x}\right)}{\partial t}=\frac{n e E_{x}}{m}-n v_{m} v_{x}, \\
& \frac{\partial\left(n v_{y}\right)}{\partial t}=\frac{n e E_{y}}{n}-n v_{m} v_{y},
\end{aligned}
$$




$$
\frac{\partial(n U)}{\partial t}=n e\left(E_{x} v_{x}+E_{y} v_{y}\right)-n v_{u}\left(U-U_{o}\right)-n v_{i} \varepsilon_{i}
$$

where $v_{\mathrm{i}}$ is the ionization collision frequency, $m$ is the electron mass, $v_{m}$ is the electron to neutral molecule momentum transfer frequency, $U$ is the electron kinetic energy, $v_{u}$ is the electron to neutral energy transfer frequency, $U_{0}$ is the average neutral encrgy, and $\varepsilon_{\mathrm{i}}$ is the average neutral ionization potential. The equations are specialized to air by taking $U_{0}=$ $0.025 \mathrm{eV}$ and $\varepsilon_{\mathrm{i}}=14 \mathrm{eV}$. The electron distribution function is assumed to be Maxwellian. We neglect convection, magnetic forces, pressure gradients, and heat flows. We ignore electron losses due to atomic and molecular processes, such as attachment and recombination, as well as diffusion. Electron generation by photoionization is also neglected.

The collision frequencies used in the code for air are analytic fits to two kinds of data. Below electron energies of $150 \mathrm{eV}$, the data is from electron swarm measurement; whereas, above $150 \mathrm{eV}$, the data is from theoretical calculations with a Maxwellian velocity distribution. 3,4 These collision frequency fits are those previously used for microwave breakdown in low-pressure air $r^{5,6}$ and microwave propagation in $t^{t}: e$ earth's atmosphere. ${ }^{7-9}$ These collision frequencies are assumed to scale directly with neutral pressure.

In addition, electron pulse charging is asstimed to occur instantly so that the real experimental problem of premature breakdown from effects, such as field emission or surface flashover, is ignored. Also the laser deposition of initial electrons is presently assumed to be instantaneous. We thus ignore detailed modeling of the laser ionization.

\subsection{Computational geometry}

Figure 1 shows the geometry for computational solution of the governing equations. The coordinate system is a $2 \mathrm{D}$, rectangular, $x-y$ system. The coordinate $z$ extends out of the plane of the figure. The space between the parallel metal plates at $y=0$ and $y=+g$ is partitioned by a rectangular mesh. Solution points for the electromagnetic variables are located to create a staggered solution grid. Similar grids have resulted in convenient spatial differencing of Maxwell's equations in 2D, explicit, finite difference, electromagnetic scattering codes. ${ }^{10}$ As denoted in the box at the bottom of Fig. $1, \mathrm{E}_{\mathrm{x}}$ is solved at even grid points along odd horizontal $(x-z)$ planes. The lowermost of these planes coincides with the bottom metal plate; whereas, the uppermost coincides with the top metal plate. Since these plates are perfect conductors, $E_{x}$ is zero along them. $E_{y}$ is calculated at odd grid points along even horizontal planes, and $\mathrm{H}_{z}$ is calculated at even grid points along the same planes. The electron fluid variables, $n, v_{x}, v_{y}$, and $U$, are evaluated at the grid points for $H_{z}$. A rectangle of grid points, consisting of those for $E_{x}, E_{y}, H_{z}$, and the unallocated grid point directly beneath that for $E_{y}$, constitutes a grid cell. The lower left grid cell, which includes the coordinate origin in Fig. 1 , is replicated in the $\mathbf{x}$ and $\mathbf{y}$ directions to complete the finite difference grid.

\subsection{Numerical solution}

The spatial derivatives in Eqs. (1)-(3) are replaced with central finite differences. The left-hand sides of Eqs. (5)-(7) are rewritten as time derivatives of $v_{x}, v_{y}$, and $U$. Seven ordinary differential equations (ODEs) in time then result for each cell of four grid points. The global set of ODEs for all the grid cells is solved by time integration with the block-iterative, optionally stiff, implicit, variable step solver GEARBI. ${ }^{11}$

GEARBI has several attractive features for problems involving gas breakdown and electromagnetic wave propagation. The variable integration step allows reduction of problem solution time, as compared to a fixed step solver set at a small step for good solution resolution. During periods of rapid avalanche ioniz tion, the code with GEARBI can take small time steps of the order of the inverse of the ionization rate. Afer the ionization slows down significantly or ceases, the code can speed up, using larger time steps. In the case of electromagnetic wave propagation, these steps can somewhat exceed the Courant limit. The Courant limit for stability of Maxwell's equations with explicit finite differencing is the time step limit given by $\Delta t_{1}=\Delta x / c$ in one dimension and $\Delta t_{2}=\left(\overline{\Delta x}^{-2}+\overline{\Delta y}^{2}\right)^{1 / 2} / c$ in two dimensions. ${ }^{10,12}$ The quantity $\Delta x$ is the grid spacing in $x$ direction, $\Delta y$ is the grid spacing in the $y$ direction, and $\mathrm{c}$ is the speed of light in vacuum. For a given computer, the block-iterative treatment allows solution of larger problem grids than is possible with other types of treatment because the memory requirement is less. For the gain in grid size, more time and effort must be invested to create the required user-supplied subroutines. The stiff equation system option also allows some highly significant reduction of 


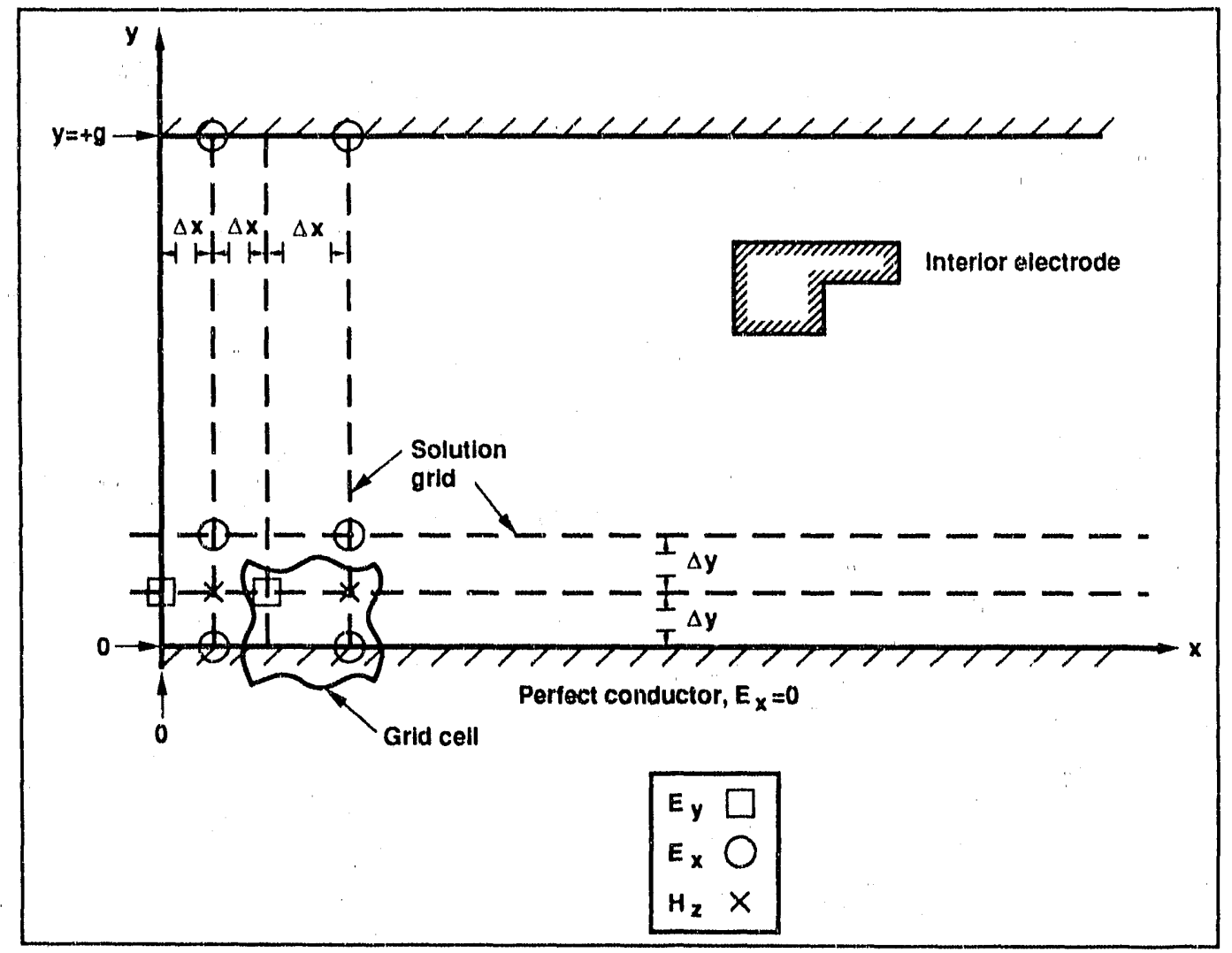

Fig. 1. Solution geometry for the electron fluid code.

problem solution time, since it causes the solver largely to ignore low-amplitude, high-frequency oscillations in the solution.

\section{MOdeling PaRAllel Plate CaPaCitor SWitches}

The 2D electron fluid code was first applied to a parallel plate capacitor switch with a gap of $100 \mu \mathrm{m}$, an applied voltage of $266 \mathrm{kV}$, and a pressure of $350 \mathrm{~atm}$. The results of these calculations agreed extremely well with the predictions of the circuit code. ${ }^{13,14}$ The electron drift velocity from these 2.D calculations agreed well with experimental results for the range, $0.1 \leq \mathrm{E} / \mathrm{p} \leq 16 \mathrm{~V} /(\mathrm{cm}$-torr), where $\mathrm{E}$ is the electric field between the plates in $\mathrm{V} / \mathrm{cm}$, and $\mathrm{p}$ is the pressure in torr. In addition, the $\alpha / \mathrm{p}$ from the $2 \mathrm{D}$ code results was in good agreement with experimental results for the range, $46 \leq \mathrm{E} / \mathrm{p} \leq$ $100 \mathrm{~V} /(\mathrm{cm}$-torr). The quantity $\alpha$ is the first Townsend coefficient. These favorable comparisons with experimental results give confidence in the soundness of both codes.

\section{A SIMPLE PULSE GENERATOR SWITCH}

A gas avalanche switch, which is slightly more sophisticated than the parallel plate capacitor switch, may be made by placing a center electrode between the plates of the parallel plate capacitor switch. This new version is suitable for a pulse power linac or a pulse generator. When a properly configured center electrode is charged to a suitable high voltage with a suitable gas pressure, this switch is predicted to produce electromagnetic pulses with picosecond rise times and durations. ${ }^{13-15}$

Figure 2 shows a simple model for such a switch. The parallel plates at the top and bottom of the figure are initially at ground potential. The pressure of the air between the plate is from 7-700 atm. A rectangular electrode with bevelled corners is centered between the parallel plates and charged to a positive high voltage $\mathrm{V}_{0}$. The gap between this center electrode and the bottom plate is uniformly filled with $1.7 \times 10^{13}$ laser-induced electrons for an assumed depth of $1 \mathrm{~m}$ 


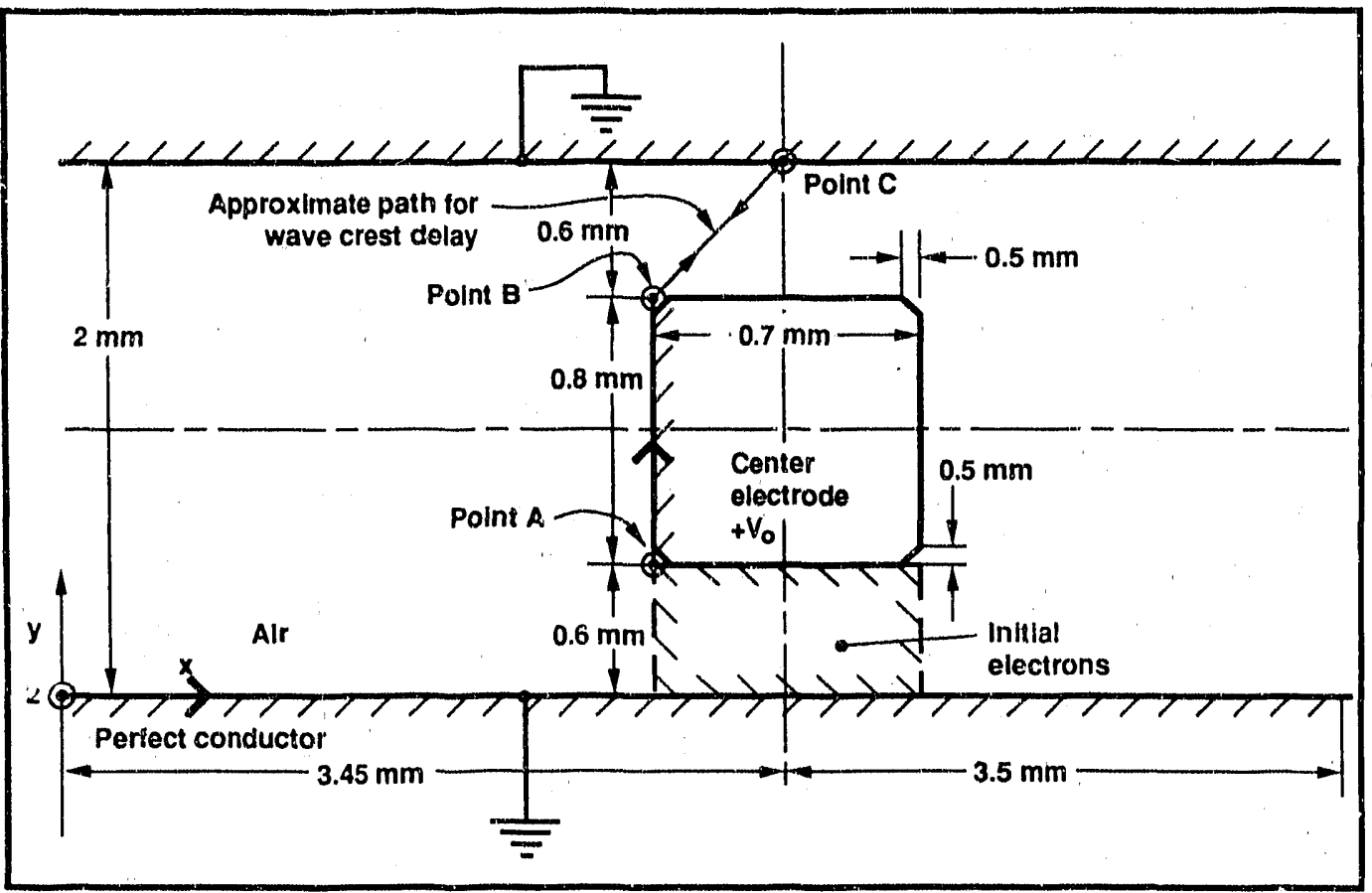

Fig. 2. The pulse generator switch model.

perpendicular to the plane of the figure. This gap is the lower gap. The space between the center electrode and the upper plate is the upper gap. For center electrode voltages from $227 \mathrm{kV}$ to $3.90 \mathrm{MV}$, computations predict that this geometry produces electromagnetic waves of about $10 \mathrm{ps} \mathrm{FWHM}$ and $20 \mathrm{GHz}$ bandwidth. The range of voltage for production of these pulses is most likely even greater, as long as the air pressure scales properly. The waves propagate outward from the center electrode to the left and right boundaries of the figur".

The solution space extends from $3.45 \mathrm{~mm}$ to the left of the center electrode vertical center line to $3.50 \mathrm{~mm}$ to the right. of that line. Transverse electromagnetic (TEM) mode boundary conditions are imposed at the left and right free space boundaries to minimize the amplitude of any inwardly traveling reflected waves, which may be generated at these grid boundaries by the outwardly traveling waves. At the left boundary, the imposed condition is $E_{y}=\eta H_{z}$, where $\eta$ is the free space intrinsic impedance, $\left(\mu_{0} / \varepsilon_{0}\right)^{1 / 2}$. At the right boundary, the conditions are $H_{z}=E_{y} / \eta$ and $E_{x}=0$. On the vertical faces of the perfectly conducting center electrode, $E_{y}=0$. On the horizontal faces, $E_{x}=0$.

The finite element electrostatic code STAT2D gives the initial electric field distribution. This distribution is used as the initial electric field conditions for the electron fluid code simulations. Figure 3 shows the initial distribution of $E_{y}$. The region of zero electric field at the center of the $x$-y plane corresponds to the center electrode. As specified by the boundary conditions, $\mathrm{E}_{\mathrm{y}}$ is zero along the two vertical faces of the center electrode. Initially, the absolute value of $\mathrm{E}_{\mathrm{y}}$ is greatest along the two horizontal faces. Along these faces, the absolute value of $E_{y}$ peaks near the corners, since these are the regions of greatest electric field enhancement. In addition, $\mathrm{E}_{\mathrm{y}}$ is negative below the horizontal center line of the center electrode and positive above it.

\section{PULSE GENERATION AT KILO'OLT VOLTAGES}

When the computer code simulation starts with the applied voltage on the center electrode at $292.4 \mathrm{kV}$ and the air pressure at $27.2 \mathrm{~atm}$, the voltage between the center electrode and the lower plate drops toward zero in about. $3 \mathrm{ps.} \mathrm{This}$ bchavior is shown in Fig. 4, which displays the waveform of the voltage between the center electrode and the lower plate close to the vertical center line in Fig. 2. This waveform begins negative because the potential of the lower plate is referred to that of the center electrode. After rebounding slightly more negative at $4 \mathrm{ps}$, this voltage slowly drops off to zero at $28 \mathrm{ps}$. This voltage ends up slightly positive at the termination of the simulation at $36.5 \mathrm{ps}$. 


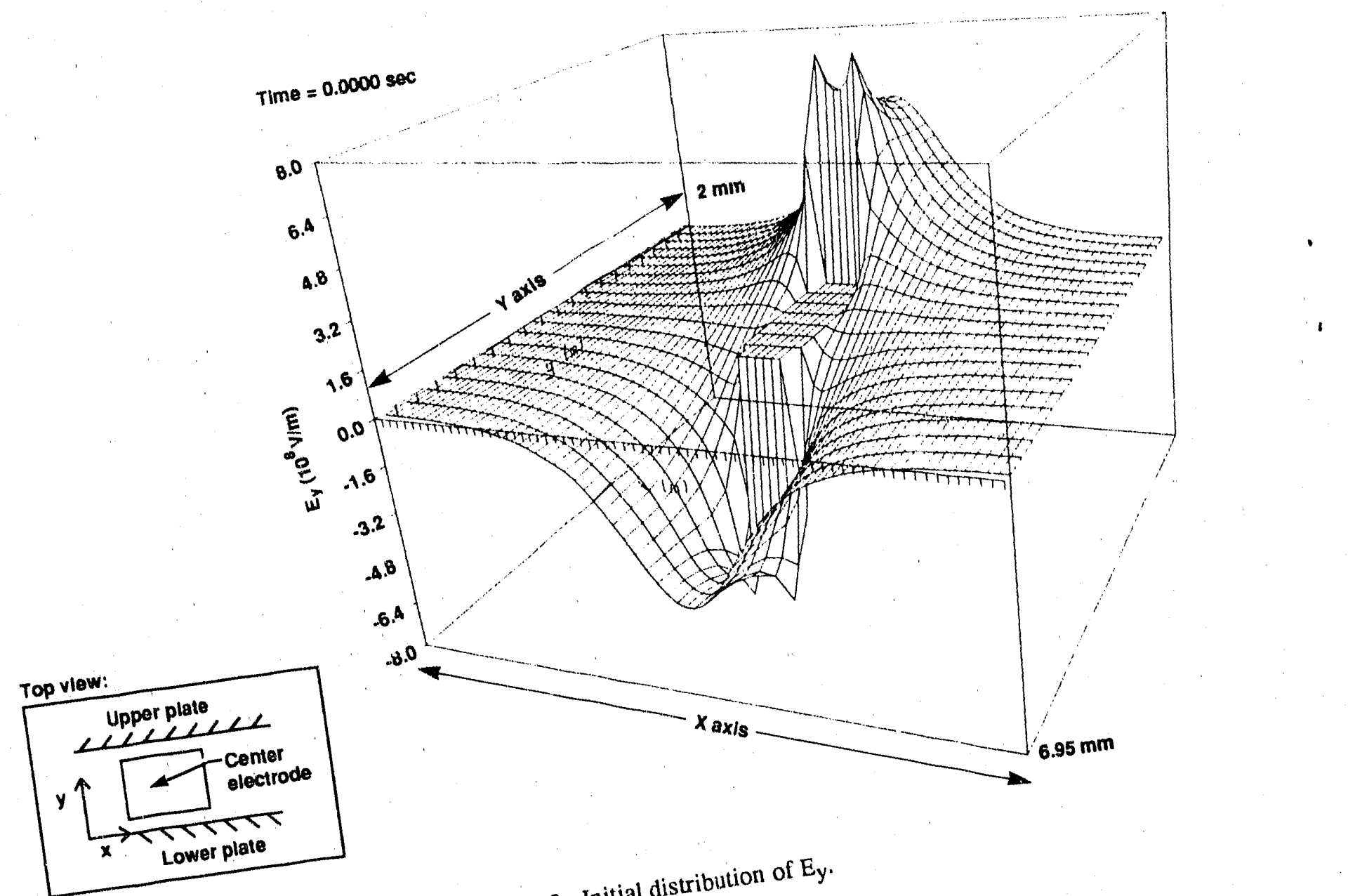

Fig. 3. Initial distribution of Ey

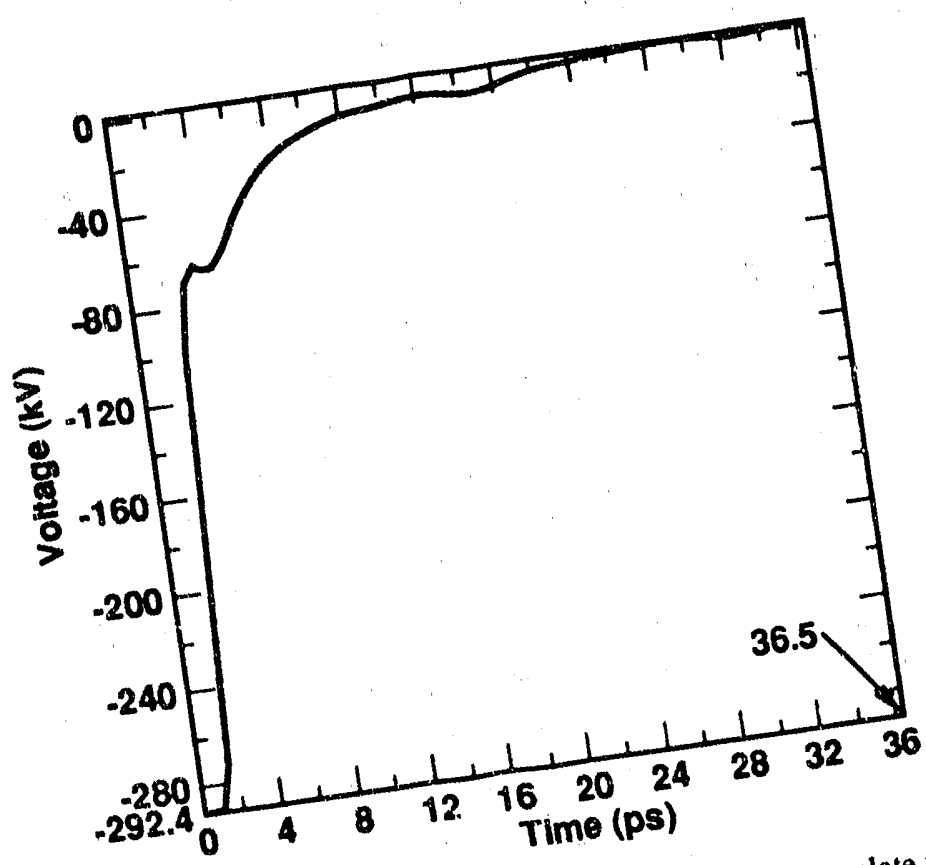

Fig. 4. Waveform of the voltage betwe.n 6 
This initially rapid voltage collapse is caused by a large, rapidly increasing flow of avalanche electrons toward the center electrode. This current generates electromagnetic waves, which propagate out to the left and right boundaries. The $\mathrm{E}_{\mathrm{y}}$ component of the waves is shown in Fig. 5 at $11.0 \mathrm{ps}$ into the simulation. In the near $\mathrm{x}-\mathrm{E}_{\mathrm{y}}$ plane, which corresponds to the surface of the lower parallel plate, two positive waves have moved out to the free space boundaries. The fronts of these waves have just hit the boundaries. This impact can be seen in Fig. 6, which shows the waveform of the voltage, $\int_{0}^{g_{E}} E_{y}$, between the parallel plates at the right boundary. The wave crests at lower plate hit the boundaries later at about $14.5 \mathrm{ps}$. This time slightly precedes the first voltage peak in Fig. 6 at 15 ps. Discernible wave crests develop at the far x-Ey plane, which corresponds to the surface of the upper plate, at about 12 ps. These upper plate crests hit the free space boundaries at about $16 \mathrm{ps}$, slightly before the second peak in Fig. 6 at 16.5 ps. Since the voltage between the plates is the integral of $E_{y}$, its peaks do not quite correspond in time to the incidence at the boundaries of the $E_{y}$ wave crests along the plates. As one moves from the lower plate toward the upper plate in Fig. 5, the wave crests for fixed y lag behind the wave crests at the lower plate.

The curious bipolar spikes between the center electrode and bottom plate are believed to be noise from the initial $\mathrm{H}_{\mathrm{z}}$ component. Thi: component appears around the center electrode during the first time step of the simulation. The $\mathrm{E}_{\mathrm{x}}$ and $\mathrm{E}_{\mathrm{y}}$ ficld components calculated by STAT2D at the center electrode boundary are thought to be inaccurate, since they are extrapolations of spatial derivatives of the electric scalar potential determined at the finite element Gauss points. The use of spatial derivatives of these inaccurate field components in Eq. (3) causes even more aggravated inaccuracies. These inaccuracies result in imperfect cancellation of the right-hand terms in Eq. (3). This imperfect cancellation of terms gives a time derivative for $\mathrm{H}_{\mathrm{z}}$ all around the perimeter of the center electrode at zero time, which is not zero. This leads to checkerboard-like noise in $\mathrm{H}_{\mathrm{z}}$ all around the boundary of the center electrode at $0.5 \mathrm{ps}$, the second output time. This noise

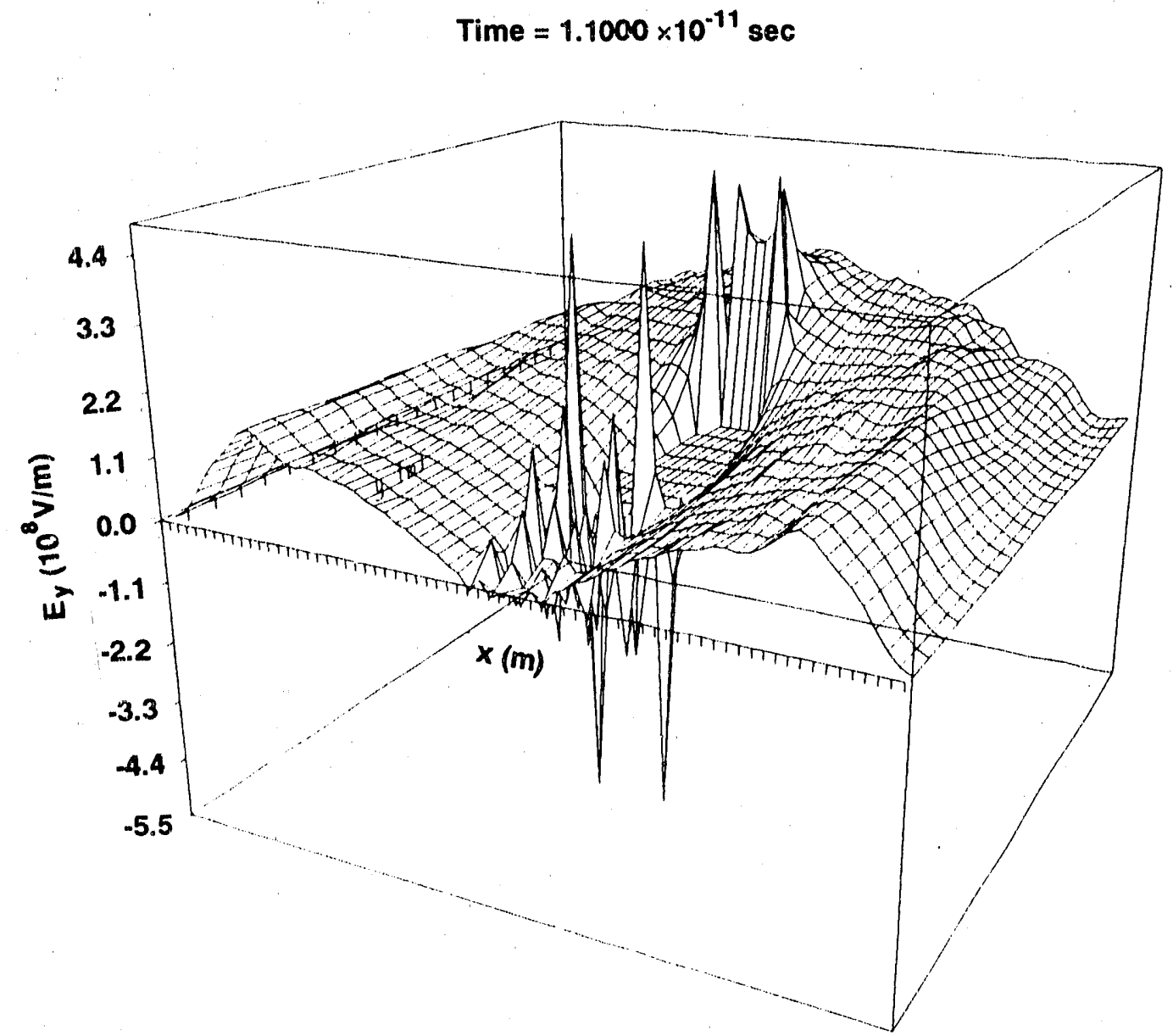

Fig. 5. Ey at $11 \mathrm{ps.}$ 


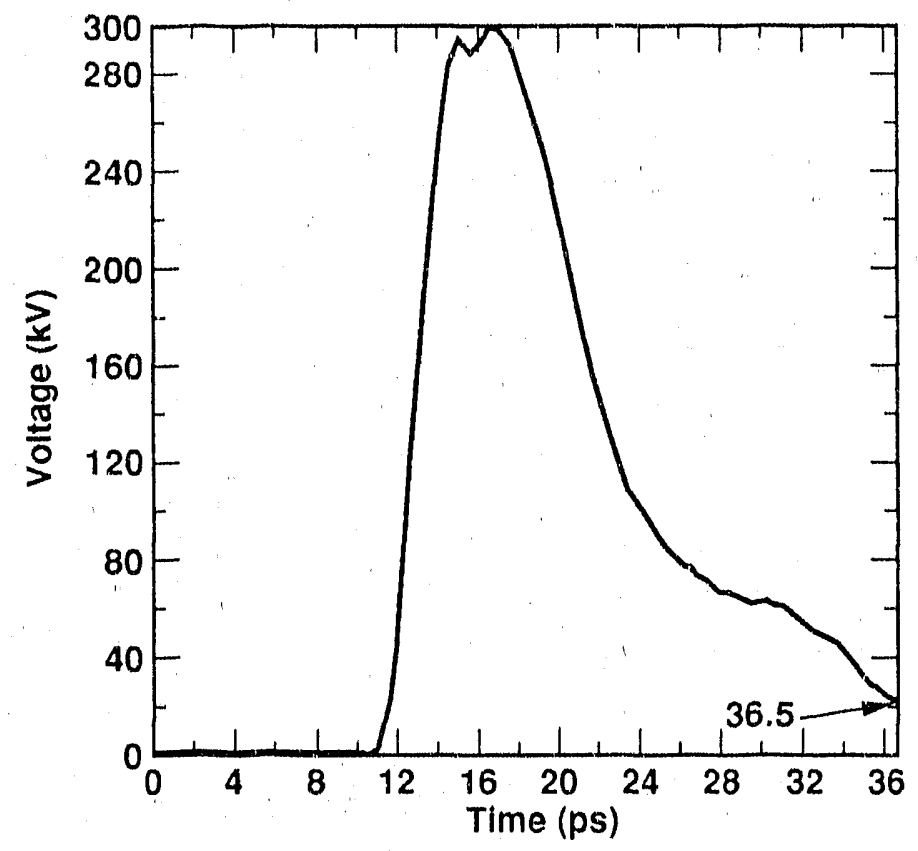

Fig. 6. Voltage waveform at right boundary at $292.4 \mathrm{kV}$ and $27.2 \mathrm{~atm}$.

extends well into the upper gap toward the upper plate. This disturbance thus appears in the upper gap long before it could physically propagate from the lower gap, where the electron avalanching occurs.

In addition to strong waves in $E_{y}$ and $\eta H_{z}$ with amplitudes of the order of $2 \times 10^{8} \mathrm{~V} / \mathrm{m}$, weaker waves in $E_{x}$ with amplitudis of the order of $5 \times 10^{7} \mathrm{~V} / \mathrm{m}$ also propagate out from the center electrode in complicated patterns. These $E_{\mathrm{X}}$ waves are probably generated by the vertical variation of the electric field in the lower gap during the avalanche, the 2D nature of the center electrode, and the dynamic vertical variation of $\mathrm{H}_{\mathrm{z}}$. The generation, propagation, and reflection of waves around the center electrode are quite complicated. These effects must cause the lag of the $E_{y}$ wave crests in the far $x-E_{y}$ plane with respect to those in the near $x-E_{y}$ plane. Since $E_{x}$ is dynamic, the generated mode structure is not purely TEM.

As shown in Fig. 6, the peak pulse voltage is $300.2 \mathrm{kV}$, the $10-90 \%$ rise time to the peak pulse voltage is $2.41 \mathrm{ps,}$ the FWHM is $9.11 \mathrm{ps}$, and the pulse duration is greater than $26 \mathrm{ps}$. A slight negative precursor precedes the positive pulse. Of the initial electrostatic energy of $3.34 \mathrm{~J} / \mathrm{m}, 55.4 \%$ has crossed the free space boundaries by $36.5 \mathrm{ps}$. The peak pulse voltage is a $2.67 \%$ enhancement of the applied voltage on the center electrode. The tail on the voltage pulse appears to be due to the slow decay of the electric field in the upper gap. Figure 7 shows the frequency spectrum of the voltage pulse in Fig. 6. The spectral peak is at $\mathrm{dc}$, and the $3 \mathrm{~dB}$ bandwidth is $23.94 \mathrm{GHz}$ under the assumption that the voltage pulse drops discontinuously to zero at $36.5 \mathrm{ps}$.

Very similar results occur at $227 \mathrm{kV}$ on the center electrode with the air pressure lowered in direct proportion to the voltage. ${ }^{15}$ This scaling of the pressure keeps the initial nominal $\mathrm{E} / \mathrm{p}$ at the center electrode constant. Reduction of this nominal $\mathrm{E} / \mathrm{p}$ causes a lengthening of the induced voltage pulse rise time, FWHM, and duration. Increase of this quantity causes an increase in the peak pulse voltage and some reduction in the rise time and FWHM. At $17 \mathrm{~atm}$, the rise time is $2.56 \mathrm{ps}$, the FWHM is $8.98 \mathrm{ps}$, and the peak pulse voltage is $236.6 \mathrm{kV}$. At $1 \mathrm{~atm}$, the rise time is $1.51 \mathrm{ps}$, the FWHM is $7.12 \mathrm{ps}$, and the peak pulse voltage is $277.7 \mathrm{kV}$. Several induced voltage pulse characteristics for the center electrode voltage at $227 \mathrm{kV}$ are shown in Table 1 for variation of the air pressure from 17-1 atm. 


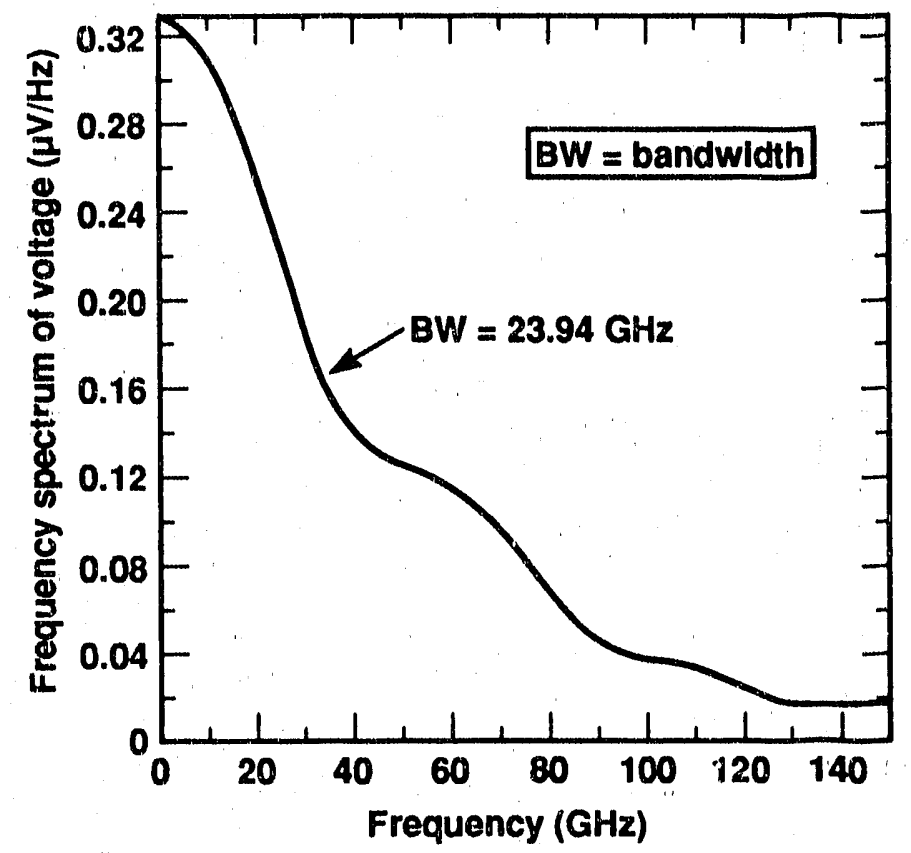

Fig. 7. Frequency spectrum of the voltage at $292.4 \mathrm{kV}$ and $27.2 \mathrm{~atm}$.

Table 1. Variation of right side voltage pulse characteristics with air pressure at $227 \mathrm{kV}$ center electrode voltage.

\begin{tabular}{|cccc|}
\hline $\begin{array}{c}\text { Air pressure } \\
(\text { atm) }\end{array}$ & $\begin{array}{c}\text { Rise time } \\
(\mathrm{ps})\end{array}$ & $\begin{array}{c}\text { FWHM } \\
\text { (ps) }\end{array}$ & $\begin{array}{c}\text { Peak voltage } \\
(\mathrm{kV})\end{array}$ \\
\hline 17 & 2.56 & 8.98 & 236.6 \\
15 & 2.28 & 8.38 & 240.5 \\
7 & 1.87 & 7.57 & 264.2 \\
1 & 1.51 & 7.12 & 277.7 \\
\hline
\end{tabular}

\section{PULSE GENERATION AT MEGAVOLT VOLTAGES}

Induced voltage pulses with similar characteristics also occur with $3.889 \mathrm{MV}$ on the center electrode and $700 \mathrm{~atm}$ pressure. Figure 8 shows the right side induced voltage waveform as the solid curve. The rise time is $2.04 \mathrm{ps}$, the FWHM is $7.88 \mathrm{ps}$, the peak voltage is $4.769 \mathrm{MV}$, and the duration is greater than $20.5 \mathrm{ps}$. The peak voltage represents a $22.6 \%$ enhancement of the applied voltage. By $29.5 \mathrm{ps}, 71.4 \%$ of the initial electrostatic energy has crossed the boundaries. With the assumption of an abrupt drop of the pulse voltage to zero at $29.5 \mathrm{ps}$, the bandwidth is $29.8 \mathrm{GHz}$.

When the initial, laser-activated electrons are concentrated intw a more narrow column, a higher peak voltage occurs at the right boundary. The dashed curve in Fig. 8 shows the voltage waveform for such a case. In this case, $1.2 \times 10^{12}$ initial electrons uniformly fill a $50 \mu \mathrm{m}$ wide column, which bridges the center electrode and the lower plate. This narrow column is centered on the vertical center line in Fig. 2. The rise time of the dashed curve is $1.72 \mathrm{ps,} \mathrm{the} \mathrm{FWHM} \mathrm{is}$ $7.39 \mathrm{ps}$, and the peak pulse voltage is $5.378 \mathrm{MV}$. This peak voltage is a $38.3 \%$ enhancement of the applied voltage. In this casc, $82.9 \%$ of the initially stored electrostatic energy crosses the boundaries by $29.5 \mathrm{ps}$. The bandwidth is $30 \mathrm{GHz}$. 


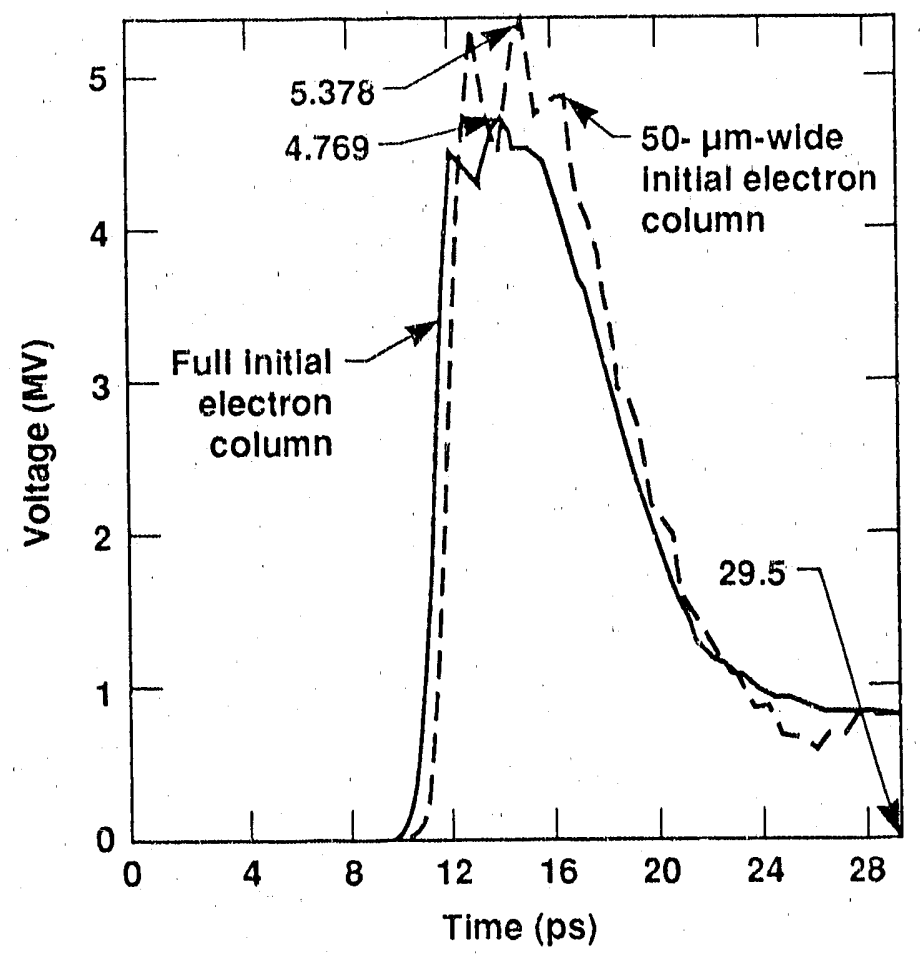

Fig. 8. Voltage waveforms at the right boundary for $3.889 \mathrm{MV}$ and $700 \mathrm{~atm}$.

\section{THE GENERATION OF LONGER PULSES BY VOLTAGE DETUNING}

It is possible to lengthen the FWHM and the duration of the induced voltage pulses from this gas avalanche switch by decreasing the applied voltage at a fixed pressure. Figure 9 shows a right side voltage waveform for $48.8 \mathrm{kV}$ and $8 \mathrm{~atm}$ pressure. The rise time is $14.7 \mathrm{ps,} \mathrm{the} \mathrm{FWHM} \mathrm{is} 28.9 \mathrm{ps}$, the duration is slightly greater than $109 \mathrm{ps,}$ and the peak voltage is $18.54 \mathrm{kV}$. The bandwidth is $9.28 \mathrm{GHz}$. The peak value of this pulse is $38.0 \%$ of the voltage applied to the center electrode.

Table 2 compares voltage pulse characteristics for three center electrode voltages at roughly constant air pressure. Detuning of the applied voltage dramatically lowers the amplitude of the pulse.

Table 2. Variation of right side voltage pulse characteristics at roughly 8 atm air pressure.

\begin{tabular}{|ccccccc|}
\hline $\begin{array}{c}\text { Applied voltage } \\
(\mathrm{kV})\end{array}$ & $\begin{array}{c}\text { Air pressure } \\
(\mathrm{atm})\end{array}$ & $\begin{array}{c}\text { Rise time } \\
(\mathrm{ps})\end{array}$ & $\begin{array}{c}\text { FWHM } \\
(\mathrm{ps})\end{array}$ & $\begin{array}{c}\text { Pulse duration } \\
(\mathrm{ps})\end{array}$ & $\begin{array}{c}\text { Peak voltage } \\
(\mathrm{kV})\end{array}$ & $\begin{array}{c}\text { Bandwidth } \\
(\mathrm{GHz})\end{array}$ \\
\hline 227 & 7 & 1.87 & 7.57 & $>15.5$ & 264.2 & 39.6 \\
48.8 & 8 & 14.7 & 28.9 & $>109$ & 18.5 & 9.28 \\
24.4 & 8 & 70.1 & 167 & $>385$ & 1.71 & 1.71 \\
\hline
\end{tabular}

\section{THE GENERATION OF SHORTER PULSES BY WAVE INTERFERENCE}

\subsection{Pulse width reduction by pressure reduction}

It is possible to reduce the voltage pulse FWHM by reducing the pressure at a fixed voltage. Reduction in pressure reduces the voltage collapse time under the center electrode by making the initial E/p greater and the avalanche more rapid. This voltage collapse time is limited at lower pressures by the reduced number of available electrons in the gas. 


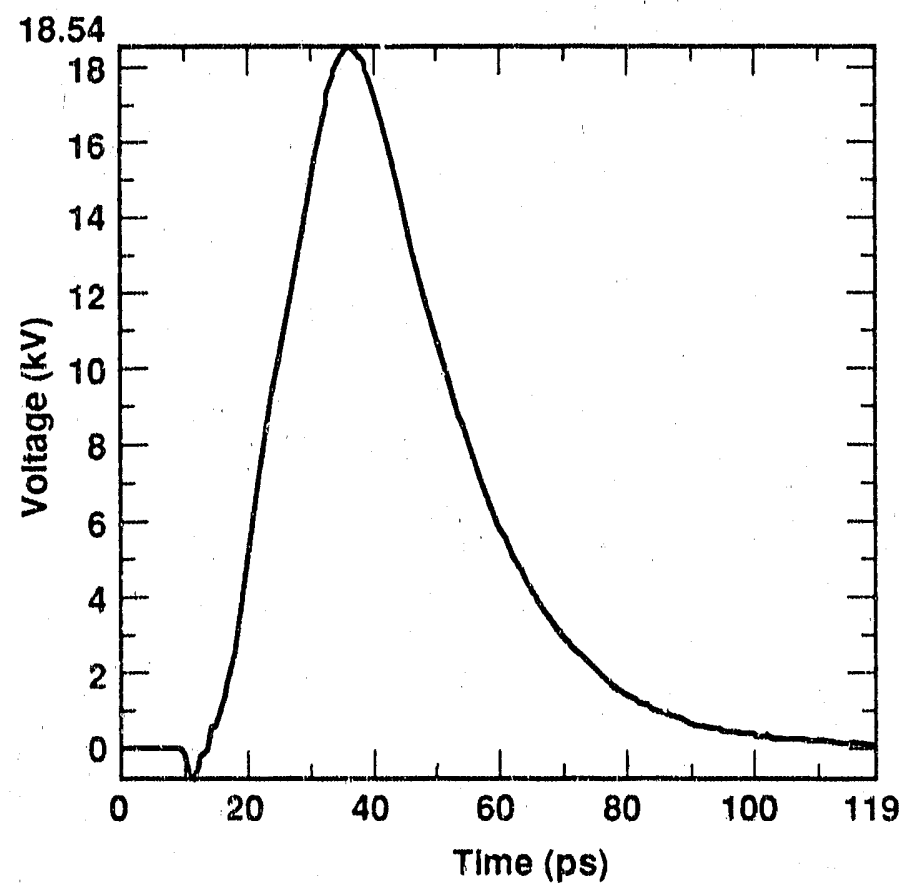

Fig. 9. Voltage waveform at the right boundary for $48.8 \mathrm{kV}$ and $8 \mathrm{~atm}$.

Calculations show that the reduction in FWHM caused by decreasing the pressure is relatively modest. Table 1 shows that a reduction in pressure from $17 \mathrm{to} 1 \mathrm{~atm}$ produces a reduction in FWHM of $1.86 \mathrm{ps}$ or $21 \%$.

\subsection{Pulse width reduction by size reduction}

Another limit on the pulse width must be imposed by the size of the physical structure. The delay in the arrival of the wave crests along the upper and lower plates partly determines the pulse width. This delay is probably given by a path difference like that from point $A$ to point $B$ to point $C$ and back to point B in Fig. 2. This trajectory is indicated in the figure by the artowheads at the left sijde of the center electrode. The path difference just defined has a delay given by $\tau=[\mathrm{h}+$ $\left.2\left((w / R)^{2}+g_{u}{ }^{2}\right)^{1 / 2}\right] / c$. The quankity $h=A B$ is the height of the center electrode, $w$ is the width of the center electrode, and $\mathrm{g}_{\mathrm{a}}$ is the electrode to upper plate gap. Substitution of the correct dimensions gives $\tau=7.3$ ps. Thus the size of the center electrode and the plate spacing seern to limit the pulse width. Reduction in these dimensions should give a reduction in pulse width.

\subsection{Pulse width reduction by wave interference}

There appears to be a way to reduce the voltage pulse FWHM without reducing the air pressure or the dimensions of the structure. This way is to trigger the upper gap slightly after the lower gap. If the avalanches in the two gaps are fairly similar, a roughly equal amplitude, negative polarity electromagnetic wave will occur at the upper gap. With no time delay in the initiation of avalanching in the two gaps, the two electromagnetic waves from the gaps should cancel almost completely at the free space boundaries. This cancellation should produce very small voltage pulses at the boundaries. With initiation of the upper gap delayed slightly from initiation of the lower gap, the wave from the upper gap should cancel only the tail of the wave from the lower gap. The width of the voltage pulse should therefore be reduced by electromagnetic wave cancellation or interference.

Figure 10 shows two right side voltage pulses generated by wave interference with two different delays betwcen laser initiation of the two gaps. Equal numbers of electrons $\left(1.7 \times 10^{13}\right.$ electrons $/ \mathrm{m}$ depth) uniformly fill each gap. The center electrode voltage is $227 \mathrm{kV}$, and the pressure is $15 \mathrm{~atm}$. When the delay is $0.5 \mathrm{ps}$, the waveform at the left of Fig. 10 occurs. This pulse has an amplitude of $51.1 \mathrm{kV}$ and a FWHN of $1.79 \mathrm{ps}$. It has a very slignt negative precursor and a 


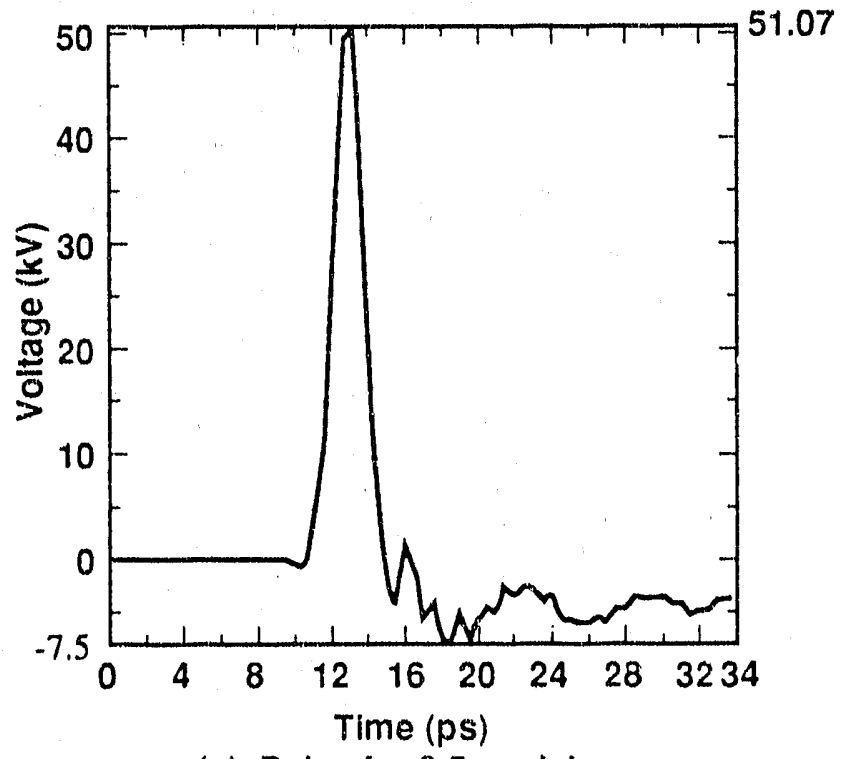

(a) Pulse for 0.5 ps delay.

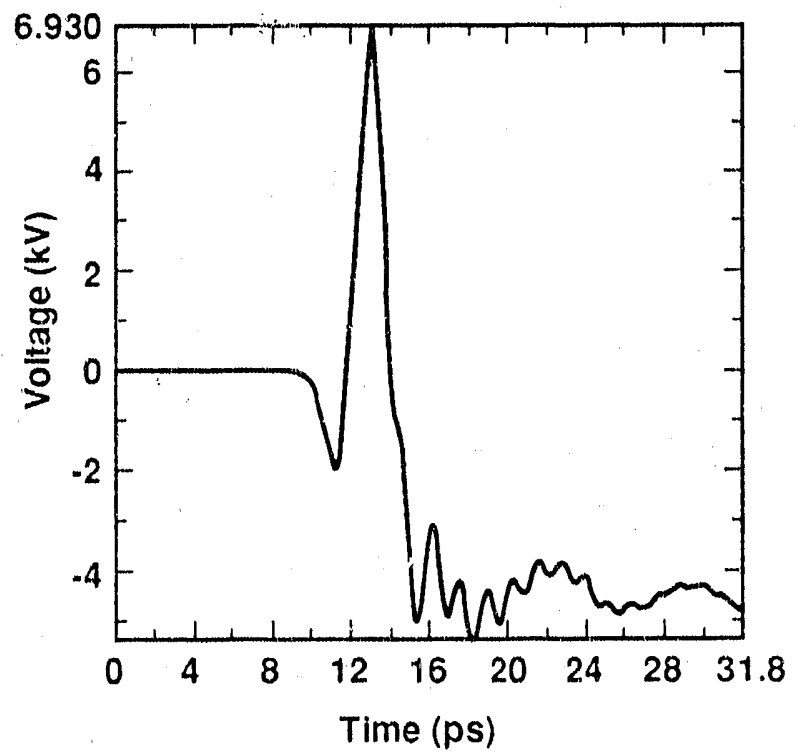

(b) Pulse for $0.1 \mathrm{ps}$ delay.

Fig. 10. Voltage waveforms generated by wave interference.

noisy trailing tail of about $7 \mathrm{kV}$ amplitude. This tail amplitude is about $14 \%$ of the pulse amplitude. The pulse amplitude is $22.5 \%$ of the applied voltage. Thus, the price of a shorter main pulse is a dramatic reduction in amplitude. The frequency spectrum of this waveform is shown at the left of Fig. 11. The $3 \mathrm{~dB}$ bandwidth is $113.3 \mathrm{GHz}$. This value is fortuitously large because the spectral cut off values fall just below the spectral dips at about 60 and $100 \mathrm{GHz}$.

A delay of $0.1 \mathrm{ps}$ for the same conditions produces the pulse at the right of Fig. 10. Because of the stronger interference, this pulse has a lower amplitude of $6.93 \mathrm{kV}$ and a shorter FWHM of $1.14 \mathrm{ps}$. The time scales of the two waveforms in Fig. 10 are slightly differnt. Unfortunately, the shorter pulse has a stronger negative precursor of about $-2 \mathrm{kV}$ and a much more prominent trailing signal. This trailing signal has an amplitude of about $5.3 \mathrm{kV}$ or $76.5 \%$ of the peak value of the pulsc. The peak value of the pulse is now only $3.05 \%$ of the applied voltage. The spectrum of this waveform is shown at the right of Fig. 11. The bandwidth is $28.09 \mathrm{GHz}$. Strong attentiation of the trailing signal will greatly increase the bandwidth.

\section{PRELIMINARY EXPERIMENTAL MEASUREMENTS}

Experimental work on gas avalanche switches has, so far, concentrated on the demonstration of picosecond switching speeds with a stripline with a series gap in it. ${ }^{16,17}$ This switching gap is excited by a high-voltage pulser. The gap is between a knife edge electrode and a plane electrode with a slightly concave contour to it. The knife edge electrode is the anode, in order to minimize field emission in the high electric field region. The switching gap is variable in length. The stripline is secured to a metal boat, which slides into a pressure vessel. The pressure vessel has two electrical feed-throughs, a set of gas fittings, and an optical port for laser illumination of the gap.

To date, only preliminary voltage holdoff tests without laser illumination have been performed. Figure 12 shows curves of the breakdown voliage threshold versus gas pressure for a $102 \mu \mathrm{m}$ electrode spacing. Both dc and an irregular ac pulse are used for excitation. For the pulse, breakdown occurred 2-6 ns after application. The top pair of curves in Fig. 12 is for the pulsed excitation. The upper of this pair of curves is for nitrogen; the lower is for argon. The bottom pair of curves is for dc. Once again, the top curve of the pair is for nitrogen. The bottom curve is for argon. The peak dc voltage shown is $15 \mathrm{kV}$ at $13.6 \mathrm{~atm}$. The peak pulsed voltage shown is $56 \mathrm{kV}$ at $13.6 \mathrm{~atm}$. Higher pressures should give higher voltage thresholds. 
Frequency spectrum of voliage $(\mu / \mathrm{Hz})$

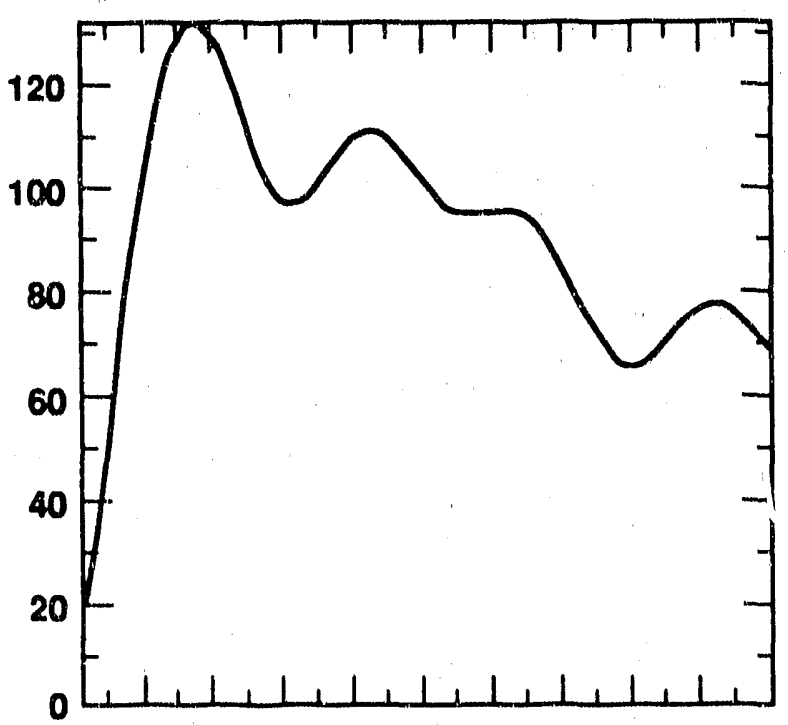

(a) Spectrum for 0.5 ps delay. The bandwidth is $113.3 \mathrm{GHz}$.

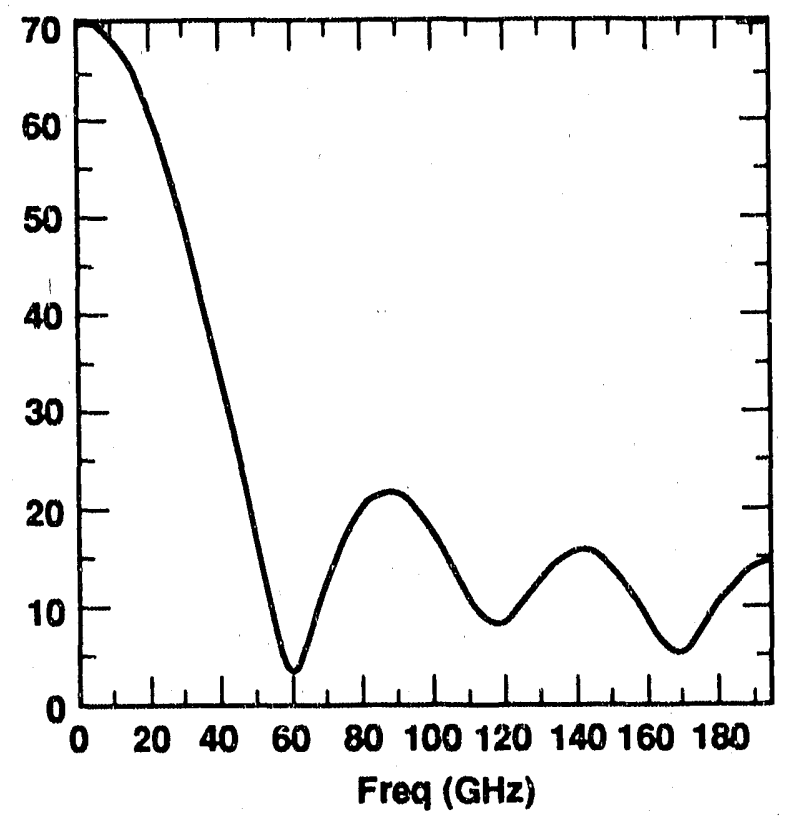

(b) Spectrum for 0.1 ps delay. The bandwidth is $28.09 \mathrm{GHz}$.

Fig. 11. Voltage spectra generated by wave interference.

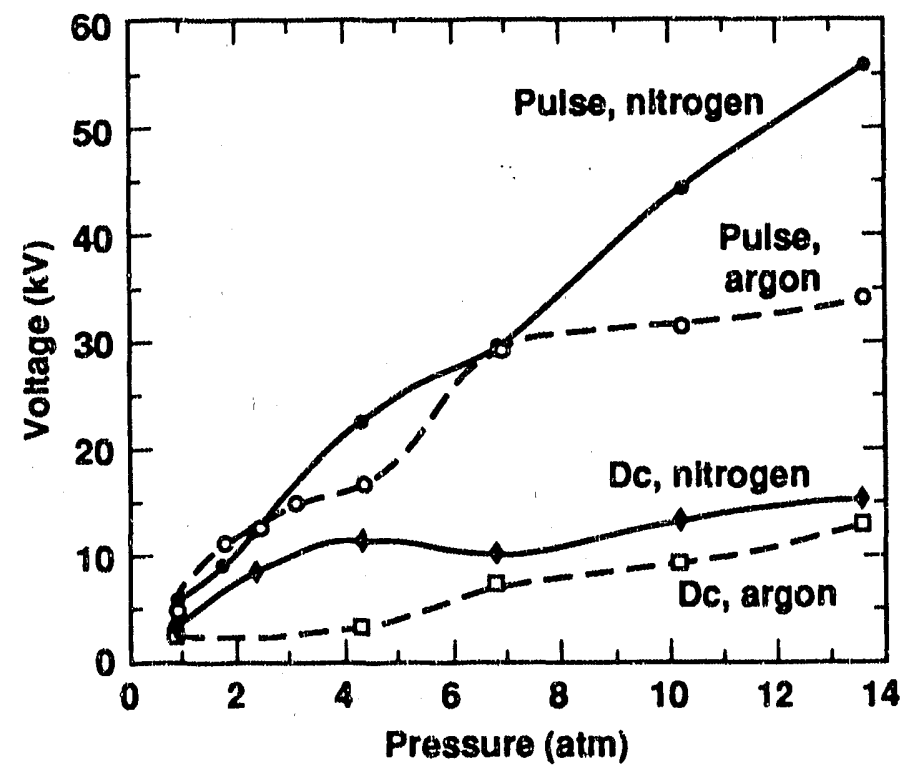

Fig. 12. Threshold voltage versus gas pressure for the stripline gap at $102 \mu \mathrm{m}$.

\section{CONCLUSIONS}

The simple, laser-activated, air gas avalanche switch computationally shows great promise for the production of high voltage $(227 \mathrm{kV}-4 \mathrm{MV})$, broadband $(20 \mathrm{GHz})$, electromagnetic pulses of picosecond rise time and duration. With fixed dimensions, the FWHM of the induced voltage pulse may be shortened to 1.14 ps by the wave interference technique. The FWHM also may be lengthened to 167 ps by low-voltage detuning at a fixed air pressure.

The conclusive experimental verification of these predictions remains, however, presendly undemonstrated. 


\section{REFERENCES}

1. F. Villa, "High Gradient Linac Prototype: A Modest Proposal," SLAC-.PUB-3875, Jan. 1986.

2. R.E. Cassell and F. Villa, "High Speed Switching In Gases," SLAC-PUB-4858, Feb. 1989; 4th Workshop: Pulse Power Techniques for Future Accelerators, Erice, Trapani, Italy, March 4--9, 1988.

3. B. Goldstein, R. Stetuner, and J. Gilbert, "The SGEMP Runaway Layer Formed in Air at Intermediate Pressures," Mission Research Corporation Technical Report MRC-R-442, Santa Barbira, CA, 1979.

4. D.H. Higgins, C.L. Longmire, and A.A. O'Dell, "A Mcthod for Estimating the X-Ray Produced Electromagnetic Pulse Observed in the Source Region of a High-Altitude Burst," Mission Research Corporation Technical Report MRC-R54 and DNA 3218T, Santa Barbara, CA, Nov, 1973.

5. D.J. Mayhall, J.H. Yec, R.A. Alvarez, and D.P. Byrne, "Two-Dimensional Electron Fluid Computer Calculations of Nanosecond Pulse, Low Pressure Microwave Air Breakdown in a Rectangular Waveguide and Their Verification by Experimental Measurement," Laser Interaction and Related Plasma Phenomena, H. Hora and G.H. Miley, eds., vol. 8 , pp. 121-137, Plenum Press, New York, 1988; UCRL-96499, Preprint, Lawrence Livermore National Laboratory, Livermore, CA, Oct. 1987.

6. G.E. Sieger, J.H. Yee, and D.J. Mayhall, "Computer Simulation of Nonlinear Coupling of High-Power Microwaves with Slots," IEEE Trans. on Plasma Science, vol. 17, no. 4, pp. 616-621, Aug. 1989; UCRL-99879, Preprint, Lawrence Livermore National Laboratory, Livermore, CA, Nov, 1988.

7. J.H. Yec, R.A. Alvarez, D.J. Mayhall, D.P. Byrne, and J. DeGroot, "Theory of Short, Intense Electromagnetic Pulse Propagation Through the Atmosphere," Phys. Fluids, vol. 29, no. 4, pp. 1238-1244, April 1986.

8. J.H. Yee, D.J. Mayhall, and R.A. Alvarez, "Physical Phenomena Induced By Passage of Intense Electromagnetic Pulses (Inciuding $\mathrm{CO}_{2}$ Lasers) Through the Atmosphere," Laser Interaction and Related Plasma Phenomena, $\mathrm{H}$ Hora and G.H. Milcy, eds., vol. 7, pp. 901-913, Plenum Press, New York, 1986.

9. G.E. Sieger, D.J. Mayhall, and J.H. Yee, "Numerical Simulation of the Propagation and Absorption Due to Air Breakdown of Long Microwave Pulses," Laser Interaction and Related Plasma Phenomena, H. Hora and G.H. Miley, eds., vol. 8, pp. 139-148, 1988; UCRL-96552, Preprint, Lawrence Livermore National Laboratory, Livermore, CA, Oct. 1987.

10. K. S. Yee, "Numerical Solution of Initial Boundary Value Prot lems Involving Maxweli's Equations in Isotropic Media," IEEE Trans. on Ant. and Propagat., vol. AP-14, no. 3, pp. 302-307, May 1966.

11. A.C. Hindmarsh, "Preliminary Documentation of GEARBI: Solution of ODE Systems with Block-Iterative Treatment of the Jacobian," UCID-30149, Preprint, Lawrence Livermore National Laboratory, Livermore, CA, 1976.

12. R.D. Richtmyer and K.W. Morton, Difference Methods for Initial-Value Problems, 2nd Edition, p. 263, Interscience Publishers, New York, 1967.

13. D.J. Mayhall and J.H. Yee, "Two-Dimensional Computer Simulation of High Pressure Air Gas Avalanche Switches," 4th Workshop: Pulse Power Techniques for Future Accelerators, Erice, Trapani, Italy, March 4-9, 1988; UCRL100431, Preprini, Lawrence Livermore National Laboratory, Livernore, CA, May 1990.

14. D.J. Mayhall, J.H. Yce, and F. Villa, "Computer Code Prediction of Picosecond Voltage Switching and TEM Wave Generation in Air Gas Avalanche Switches," 7th IEEE Pulsed Power Conference, R. White and B.H. Bernstein, eds., pp. 514-517, Publishing Services, IEEE, New York, 1989; UCRL-1(0)122, Preprint, Lawrence Livermore National Laboratory, Livermore, CA, June 1989.

15. D.J. Mayhall and J.H. Yee, "Prediction of High-Voltage, Broadband RF Pulse Generation from an Air Gas A valanche Switch," URCL-1D-103.35, Lawrence Livermore National Laboratory, Livermore, CA, March 1990.

16. M. S. DiCapua, D. Mayhall, and F. Villa, "High Pressure Gas Switch Project Quarterly Report," Microwave and Pulsed Power Engincering Thrust Area Quarterly Report, October 1987 - December 1987, W. W. Hofer, ed., pp. 13-24, Lawrence Livermore National Laboratory, Livermore, CA, Feb. 1988.

17. D.J. Mayhall, R. Kihara, and F. Villa, "High Pressure Gas Switching," UCRL-53868-88, Thrust Area Report FY88, Enginecring Research and Development, E. LaFranchi, ed., pp. 617-619, Lawrence Livermore National Laboratory, Livermore, CA, June 1988. 

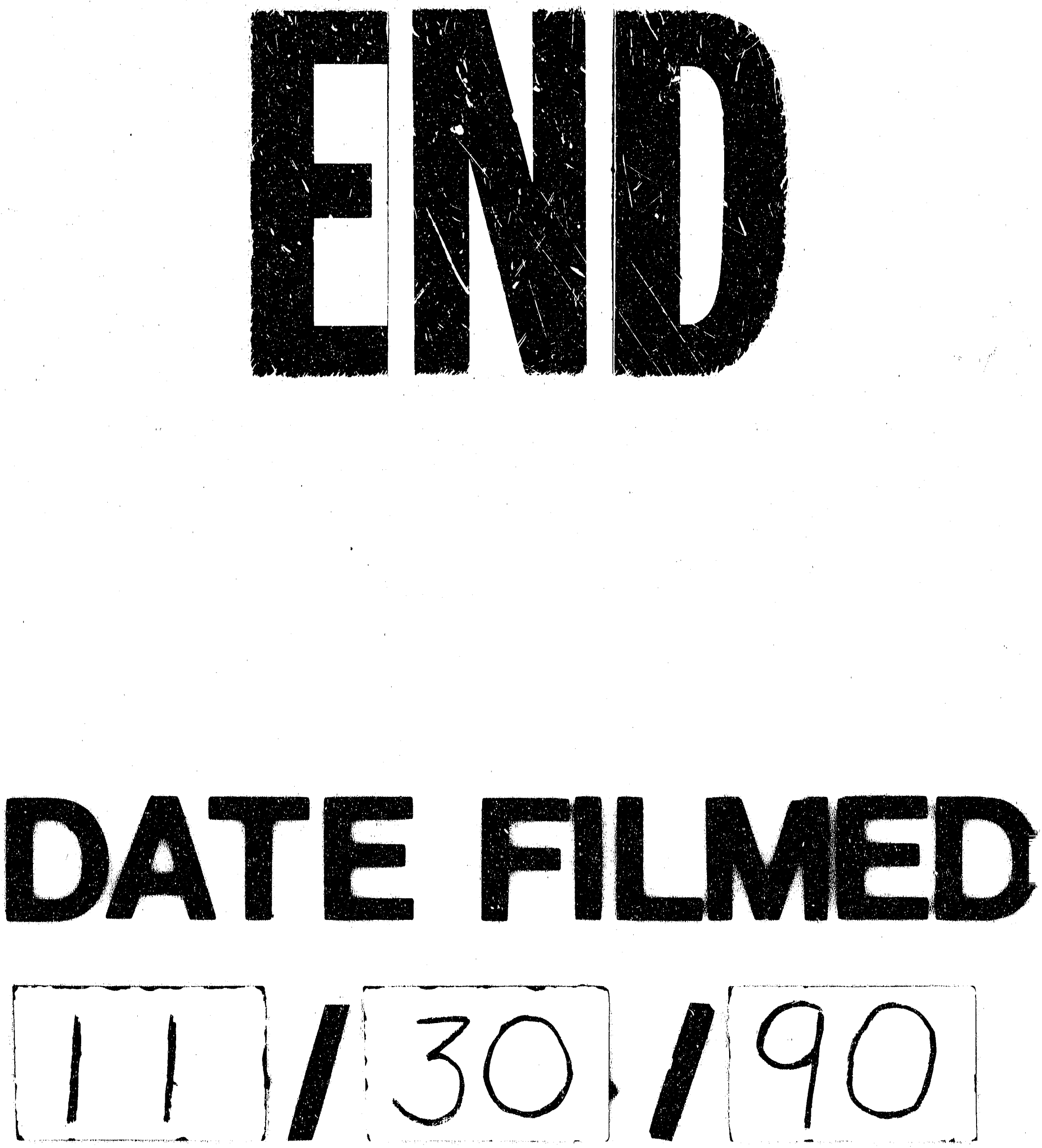
$=$ 